Jurnal Teknologi Laboratorium

Vol.8, No.2, September 2019, pp. $47-53$

ISSN 2580-0191 (Online), ISSN 2338 - 5634(Print)

DOI: $10.29238 /$ teknolabjournal.v8i2.158

Journal homepage: https://www.teknolabjournal.com/index.php/Jt//index

\title{
Effect of electromagnetic field on whole blood, biochemical and hormone level in human
}

\section{Mehmet Cihan YAVAŞ ${ }^{1 a^{*}}$, Veysi AKPOLAT ${ }^{2}$, Özkan GÖRGÜLÜ ${ }^{3}$, İbrahim KAPLAN ${ }^{4}$}

${ }^{1}$ Department of Biophysics, Faculty of Medicine, Kırşehir Ahi Evran University, Kırşehir, Turkey

${ }^{2}$ Department of Biophysics, Faculty of Medicine, Dicle University, Diyarbakır, Turkey

${ }^{3}$ Department of Biostatistics and Medical Informatics, Faculty of Medicine, Ahi Evran University, Kırşehir, Turkey

${ }^{4}$ Department of Biochemistry, Faculty of Medicine, Dicle University, Diyarbakır, Turkey

a Email address: mcihanyavas@ahievran.edu.tr

\section{HIGHLIGHTS}

Magnetic fields constantly lead to changes in the biochemistry, hormone and whole blood parameters

\section{ARTICLE INFO}

\section{Article history}

Received Date: March $19^{\text {th }}, 2019$

Revised Date: April 29th 2019

Accepted Date: September $27^{\text {th }}, 2019$

\section{Keywords:}

Electromagnetic Field

Whole Blood

Biochemical

Hormone

\begin{abstract}
A B S T R A C T
The electromagnetic field is increasing in our environment and these exposures cause concern. The aim of our study is to investigate the effects of magnetic fields generated by the hair dryers' devices used by women working in the same job on their serum biochemistry, whole blood and hormone values. The sixteen women working continuously in hairdressing salons were included in the study. Two groups of studies were designed: control ( $\mathrm{n}: 8$, mean age: $22.25 \pm 6.04)$ and experimental group ( $\mathrm{n}: 8$, mean age:23,62 \pm 6.67 ). The biochemical (median values of alanine amino transferase, aspartate aminotransferase, triglycerides and very low density lipoprotein were found high) and hormonal results of the experimental group were compared with the biochemical (cholesterol, low-density lipoprotein and very high-density lipoprotein had high median values) and hormonal results of the control group and no significant difference was found $(p>0.05)$. When the whole blood parameters were examined, the white blood cells and mean platelet volume results of the experimental group were significant $(p<0.05)$, while there was a meaningless difference between red blood cell, hemoglobin, hematocrit, mean corpuscular volume, red cell distribution width and platelet values $(p>0.05)$. It is evident from the results that occupational exposure to magnetic fields constantly leads to changes in the biochemistry, hormone and whole blood parameters of the female.
\end{abstract}




\section{INTRODUCTION}

In modern life it is now possible to see devices that produce man-made electromagnetic fields everywhere. With the development of the industry, the rapid increase of these tools and equipment has increased the anxiety of the public, and the first scientific studies on this field started in the 1970's. ${ }^{1}$ The electric field, the magnetic field and the electromagnetic field generated by the electric home appliances and the devices used in the work places have become widespread with the increase in need. ${ }^{2}$ Discussions continue in the scientific circles related to the biological effects of very low frequency electromagnetic fields on humans. The use of electric power in conjunction with urbanization and industrialization suggests recent study reports that are undesirable harmful effects on humans. ${ }^{3}$ Studies on very low frequency magnetic fields are continuing. Epidemiological studies related to childhood leukemia of low-exposed magnetic fields ( $<1$ microTesla) continue. More than 20 biophysical mechanisms related to these epidemiological studies have been investigated and still no causal link has been established., ${ }^{4,5}$ It reports recent epidemiological studies. They investigated the relationship between the risk of leukemia in children, the use of pre-natal mothers' sewing machines, the use of stereo worship, the use of television sets and hair dryers. It has been emphasized that the sustained work and measurements made by the mouthpieces of the hair dryers may increase depending on the distance. $\frac{6}{}$

\section{MATERIALS AND METHOD}

This work was carried out in approximately 100 hairdresser workplaces in Diyarbakir Office district. All participant surveys were conducted before blood samples were taken. Exclusion factors have been applied to female employees involved in the study (e.g., nonsmoking, no metabolic, systemic and other illnesses). As a result of exclusion, the sixteen female employees randomly (control group: age; $23.62 \pm 6.67$; age: $22.25 \pm 6.04$ ) were grouped into 2 groups (n: 8). Women were allowed to drink no antioxidants, tea, juice until about 3 hours before blood was taken from the employees. Blood was collected and maintained at $-20^{\circ} \mathrm{C}$ until analyzed by centrifugation at $300 \mathrm{rpm}$ for $10 \mathrm{~min}$. Serums were analyzed with fully automated analyzers. Biochemical serum results were analyzed using the photometric method with the Abbott Architect C16000 (Illinois, United States) instrument. Hormone results were analyzed using the electrochemiluminescence method with a Roche Cobas 601 instrument. The whole blood results were analyzed using the Abbott CELL-DYN Ruby instrument with multi-angle polarized light scatter separation and laser measurement technology. All participants were informed about the study and received their consent for the study. The study continued after the approval of the Ethics Committee of the Dicle University.

Specific features of hair dryers used in the study are; AC, 200-240 Volt, $50-60 \mathrm{~Hz}$, 1800-2200 Watts. Reference measurement methods are taken into account and the arithmetic mean of the measurements is calculated. Our measurements were taken at a distance of 10 $\mathrm{cm}$ and found an electric field of $73.5 \mathrm{~V} / \mathrm{m}$ and a magnetic field of $4.61 \mu \mathrm{T}$, respectively. The electromagnetic field was measured by aid of a Spectran device NF5035 (AARONIA AG, Strickscheid, Germany), using the method of six-minute measurement proposed by the International Commission on Non-lonizing Radiation Protection (ICNIRP).

The Kolmogorov-Smirnov test was used to analyze whether the data obtained in the study were normal distributions. As a result of the analysis, biochemical values were not normally distributed $(p<0.05)$. Complete blood and hormone values provide normality assumption ( $p>0.05)$. Mann Whitney $U$ test, a nonparametric test, was used to compare biochemical values that did not imply normality hypothesis. Independent $t$ test was used to compare whole blood and hormone values, which provided normality hypothesis. Participants were asked whether they had any complaints, and the distribution of the data according to the groups was converted into a quotient table. The values in the contingency table were analyzed by the Fisher Exact Chi square test. Statistical analysis of the study was conducted with SPSS 21. 0 (IBM SPSS Statistics for Windows, Version 21.0, Armonk, NY: IBM Corp., USA). 


\section{RESULTS AND DISCUSSION}

It has been determined that gender has no significant effect on the averages of age. For this reason, the analysis did not need to be used as a covariate. The mean age of the women in the experiment group was $23.62 \pm 6.67$. The average daily usage time of women in the experimental group of the hair dryer is $361.25 \pm 188.63$ minutes.

The women in the experimental group worked on average 3.6 years in the hairdressing salon. When the distance to the body during the use of the hair dryers' machine was examined, it was determined that the women were trapped at an average distance of $15.00 \pm 3.77 \mathrm{~cm}$. The complaint of the women who participated in the survey are given in Table 1 according to the groups. According to the Fisher exact test statistics, the weakness complaints of the ladies were higher than the ladies in the control group $(p<0.01)$. According to the Fisher exact test statistics, the fatigue complaints of the ladies were higher than the ladies in the control group $(p<0.05)$.

Table 1. Fisher exact test results

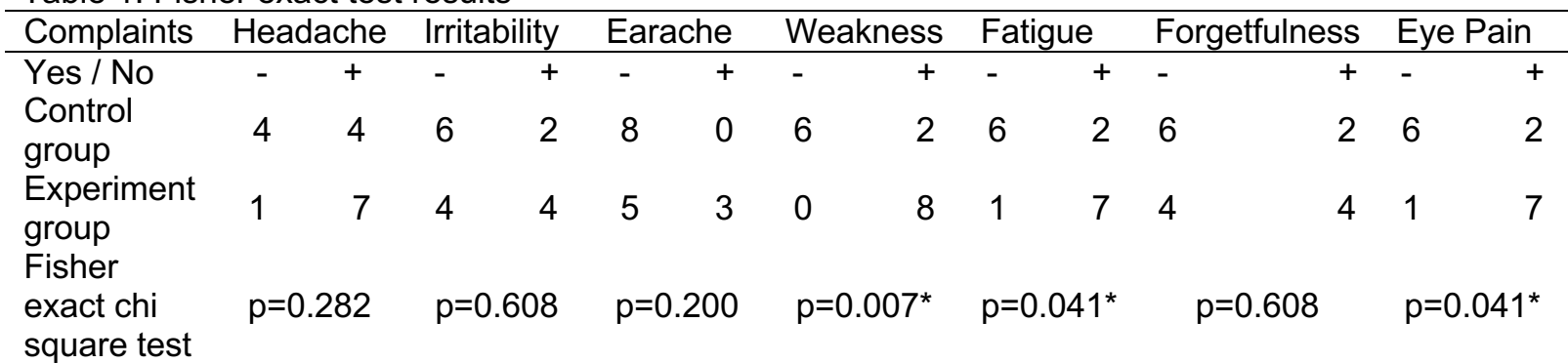

Note:

1. when compared with the control group of the experimental group (Fisher exact chi square test)

2. Symbol + for answer "yes"; symbol - for answer "no"

The explanatory statistics (mean \pm standard deviation, median) and Mann Whitney $U$ test values for female biochemistry values are summarized in Table 2. When the women's biochemical values were examined, the median values of the alanine amino transferase (ALT), aspartate aminotransferase (AST), triglycerides (TRIG), very low-density lipoprotein (VLDL) parameters of the experimental group were found higher in the control group. The median values of the cholesterol (CHOL), low density lipoprotein ( $\mathrm{LDL})$, ultra-low-density lipoprotein (UHDL) parameters of the control group were higher than the experimental group. According to Mann Whitney $U$ test results, the differences between control and experiment groups in terms of all biochemical parameters are statistically insignificant $(p>0.05)$.

The explanatory statistics (mean $\mp$ standard deviation) and independent $t$ test results for the female hormone values are given in Table 3 . According to these results, there was no statistically significant difference between experimental and control groups in terms of cortisol, estrogen and testosterone values in females $(p>0.05)$.

The statistical analysis results of the whole blood values of the female are given in Table 4. According to these results, the RBC value of the experimental group is higher than the control group. The difference between the white blood cells (WBC) values of both groups is statistically significant $(p<0.05)$. Mean platelet volume (MPV) value was higher in the experimental group than in the control group. The difference between the control group and the experimental group is statistically significant $(p<0.05)$. Differences between red blood cell (RBC), hemoglobin (HGB), hematocrit (HCT), mean corpuscular volume (MCV), red cell distribution width (RDW) and platelet (PLT) parameters were statistically insignificant $(p>0.05)$. 
Table 2. Female's biochemical results

\begin{tabular}{cccccccc}
\hline \multirow{2}{*}{ Parameters } & \multirow{2}{*}{$\begin{array}{c}\text { References } \\
\text { Ranges }\end{array}$} & Mean $\pm \mathrm{SD}$ & Median & Mean $\pm \mathrm{SD}$ & Median & $\begin{array}{c}\text { Mann } \\
\text { Whitney } \\
\text { U Test }\end{array}$ & $\begin{array}{c}\mathrm{p} \\
\text { Value }\end{array}$ \\
\cline { 3 - 6 } ALT (U/L) & $10-35$ & $12.25 \pm 5.97$ & 15.00 & $20.50 \pm 16.91$ & 12.50 & 21.50 & 0.268 \\
AST (U/L) & $10-40$ & $15.25 \pm 4.80$ & 15.50 & $20.12 \pm 16.64$ & 14.50 & 27.50 & 0.632 \\
CHOL (mg/dL) & $112-200$ & $169.12 \pm 30.59$ & 143.50 & $162.25 \pm 22.48$ & 153.00 & 26.00 & 0.528 \\
LDL (mg/dL) & $60-160$ & $85.62 \pm 28.00$ & 82.50 & $80.00 \pm 20.98$ & 75.00 & 29.50 & 0.792 \\
TRIG (mg/dL) & $50-180$ & $101.37 \pm 92.42$ & 93.50 & $126.37 \pm 70.98$ & 124.50 & 23.50 & 0.372 \\
UHDL (mg/dL) & $37-79$ & $63.25 \pm 7.47$ & 41.50 & $57.00 \pm 8.78$ & 58.50 & 18.50 & 0.154 \\
VLDL (mg/dL) & $10-32$ & $20.25 \pm 18.38$ & 19.00 & $25.25 \pm 14.05$ & 24.00 & 22.50 & 0.317 \\
\hline
\end{tabular}

Note: Data are presented as mean \pm SD and median. $p>0.05$ compared to control (Mann Whitney U test). ALT: alanine aminotransferase, AST: aspartate aminotransferase, CHOL: cholesterol, LDL: lowdensity lipoprotein, TRIG: triglyceride, UHDL: high-density lipoprotein, VLDL: very low-density lipoprotein.

Table 3. Analysis results of female hormone values

\begin{tabular}{cccccc}
\hline Parameters & $\begin{array}{c}\text { References } \\
\text { ranges }\end{array}$ & $\begin{array}{c}\text { Control group } \\
(\text { Mean } \pm \mathrm{SD})\end{array}$ & $\begin{array}{c}\text { Experimental group } \\
(\text { Mean } \pm \mathrm{SD})\end{array}$ & $\mathrm{t}$-test & $\mathrm{p}$ value \\
\hline Cortisol $(\mu \mathrm{g} / \mathrm{dl})$ & $6.2-19.4$ & $8.95 \pm 4.07$ & $6.64 \pm 2.59$ & 1.354 & 0.197 \\
Estrogen $(\mathrm{pg} / \mathrm{ml})$ & $7.6-43$ & $105.29 \pm 101.48$ & $179.28 \pm 133.07$ & -1.250 & 0.232 \\
Testosterone & $2.8-8$ & $0.23 \pm 0.06$ & $0.32 \pm 0.13$ & -1.565 & 0.140 \\
$(\mathrm{ng} / \mathrm{dl})$ & &
\end{tabular}

Note: Data are presented as mean \pm SD. $p>0.05$ compared to control (Independent t test)

Table 4. Female's whole blood results

\begin{tabular}{cccccc}
\hline Parameters & $\begin{array}{c}\text { References } \\
\text { ranges }\end{array}$ & $\begin{array}{c}\text { Control group } \\
(\text { Mean } \pm \text { SD) }\end{array}$ & $\begin{array}{c}\text { Experimental group } \\
(\text { Mean } \pm \text { SD) }\end{array}$ & t-test & p value \\
\hline WBC $(\mathrm{K} / \mathrm{hL})$ & $3.2-12$ & $6.83 \pm 1.60$ & $8.56 \pm 1.61$ & -2.164 & 0.048 \\
RBC $(\mathrm{M} / \mathrm{uL})$ & $3.2-6$ & $4.37 \pm 0.17$ & $4.29 \pm 0.41$ & 0.550 & 0.591 \\
HGB $(\mathrm{g} / \mathrm{dL})$ & $10-18$ & $13.35 \pm 0.81$ & $13.30 \pm 1.47$ & 0.084 & 0.934 \\
HCT $(\%)$ & $30-55$ & $37.52 \pm 2.03$ & $37.28 \pm 4.15$ & 0.145 & 0.887 \\
MCV (fL) & $98-120$ & $85.71 \pm 1.81$ & $86.85 \pm 3.91$ & -0.746 & 0.468 \\
RDW (\%) & $9-18$ & $15.32 \pm 0.52$ & $14.77 \pm 0.50$ & 2.137 & 0.051 \\
PLT (K/uL) & $150-500$ & $318.50 \pm 41.38$ & $280.73 \pm 96.44$ & 1.018 & 0.326 \\
MPV (fL) & $0-15$ & $7.72 \pm 0.63$ & $8.67 \pm 0.87$ & -2.495 & 0.026 \\
\hline
\end{tabular}

Note:

Data are presented as mean \pm SD. $p>0.05$ compared to control (Independent $t$ test). ${ }^{*} p<0.05$ compared to control group. ${ }^{* *} p<0.01$ compared to control group. WBC: white blood cells, RBC: red blood cell, HGB: hemoglobin, HCT: hematocrit, MCV: mean corpuscular volume, RDW: red cell distribution width, PLT: platelet, MPV: mean platelet volume.

Commercial salon-type hair dryers create a magnetic field after long-term operation. With this modeling studies, it has been emphasized that these hair dryers cause thermal effects and noises in the heads of people. ${ }^{?}$ In his analysis of measurements made by Johansen; ELF-electromagnetic fields are becoming increasingly widespread and the magnetic field created by the hair dryer forms a magnetic field of 17.44 micro tesla at $5 \mathrm{~cm}$, 0.12 micro tesla at $50 \mathrm{~cm}$ and 0.02 micro tesla at $100 \mathrm{~cm} \cdot \stackrel{2}{ }$ The results of analyzes made by the World Health Organization show that hair dryer machines generate $80 \mathrm{~V} / \mathrm{m}$ electric field at $30 \mathrm{~cm}$ distance, generate magnetic field 6-2000 microTesla at $3 \mathrm{~cm}$ distance, 0.01-7 microTesla at $30 \mathrm{~cm}$ and $0.01-0.03$ microTesla $1 \mathrm{~m}$ distance..

In a sustained study by Stronati et al. a short exposure to ELF magnetic fields of $1 \mathrm{mT}$ $(2 \mathrm{~h})$ did not show any genotoxic effect in human blood cells. A statistically significant effect has been observed although there is an effect of exposure on cell proliferation, but at this point it is difficult to interpret this effect as biological effect. ${ }^{-9}$ Biophysical and biological mechanisms have not yet been fully elucidated as low-frequency magnetic fields can affect reproduction and development. ${ }^{10}$ 
Güler and his colleagues investigated the effects of vertical and horizontal electric field on Guinea pigs. It has been reported that there is no statistical difference in some serum biochemical parameters of the electric field applied in the study. ${ }^{11}$ Daşdağ and his colleagues have shown that very low frequency electromagnetic fields do not change the hematological and immunological parameters in the work carried out on workers working in welding jobs. 12 In vivo studies of Heredia-Rojas et al. indicate that they may produce a clastogenic effect in mice after a magnetic field exposure at $60-\mathrm{Hz}, 1.5$ and $2.0 \mathrm{mT} .{ }^{-}$Alghamdi and colleagues investigated the short and long term effects of the electromagnetic fields of $0.49 \mathrm{~W} / \mathrm{kg}$ and $0.72 \mathrm{~W} / \mathrm{kg}$ SAR on the hematological parameters of mice at $900-1800 \mathrm{MHz}$ frequency. Decrease in PLT value and increase in WBC value in the study were found to be consistent with our study. $\frac{13}{-}$ Dogan and colleagues emphasized that electrical and magnetic fields generated by high voltage in the laboratory environment cause changes in trace element concentrations of rats. ${ }^{14}$ Chater and colleagues investigated the effect of static magnetic field on pregnant rats. Chater and colleagues investigated the effect of static magnetic field on pregnant rats. While the findings of WBC, RBC and HGB in our study showed similar changes with our study, PLT changes were different. While AST and PLT were significant in Chater's study, AST and ALT parameters in our study were not statistically significant compared to the control group. $\frac{15}{}$

In a study conducted by Çakir and colleagues on rats, it appears that very low frequency magnetic fields ( 3 hours a day, $0.97 \mathrm{mT}, 50$ and 100 days) reduce some blood count values. ${ }^{16}$ In our study, similar changes were observed, and blood count values increased and decreased. WBC and MPV show significant change $P<0.05$ ).

Investigators have reported that exposure to electromagnetic fields on sex hormones of wistar female rats ( $4 \mathrm{~h} /$ day and $3 \mathrm{mT}$ /day for six weeks) has an adverse effect. ${ }^{17}$ Literature on the effects of highly low-frequency electromagnetic fields on cortisol is very limited. These few studies are short-term data. ${ }^{-}$Al-Akhras and colleagues reported that the $50 \mathrm{~Hz} 25$ microtesla magnetic field had an adverse effect on the fertility of both male and female rats. $\frac{18}{}$

In our study, we found that complaints of fatigue, fatigue and eye pain were found to be meaningful in employees who used a continuous hairdryer. When the biochemical findings of our study were analyzed, no significant change in all parameters was observed. When compared to the control group, the mean values of ALT, AST, TRIG and ULDL in the experimental group increased and $\mathrm{CHOL}$ and UHDL values decreased. Statistically no difference was observed when the hormone values were examined.

However, it was noticed that the estrogen level increased in the experimental group. A significant change in the WBC and MPV values was observed in the whole blood values of our study. Our findings suggest that some of the parameters in the sera of women may have been altered by the influence of the electrical and magnetic fields generated by the hair dryer. Most of the literature information that has been made suggests that very low frequency electromagnetic fields have a negative effect on biochemical, hematologic and other parameters.

\section{CONCLUSION}

Our work has drawn attention to the effects of electrical and magnetic fields on the organism, which are made by man-made electrical devices that are constantly used by professional workers. With this work, we may be able to protect ourselves from areas we are exposed to constantly without knowing it. The fact that the literature data on this area is too small that our study may be a reference. In our work, the effects of the people who spend a lot of time in hairdressing salons and the effects of the women using these devices on the biochemistry, hormone and whole blood parameters have been examined. We believe that our work will be a useful source of concern for community health and we emphasize the need for more work. 


\section{CONFLICT OF INTEREST}

All authors state that there is no conflict of interest.

\section{REFERENCE}

1. Heredia-Rojas JA, Beltcheva M, OA. De la Fuente A, Heredia-Rodriguez O, Metcheva R, E Rodriguez-Flores L, A Santoyo-Stephano M, Castaneda-Garza E. 2017. Evidence of genotoxicity induced by $60 \mathrm{~Hz}$ magnetic fields on mice bone marrow as assessed by in vivo micronucleus t test. Acta Zool Bulg. 8: 69-75.

2. Johansen C. 2004. Electromagnetic fields and health effects-epidemiologic studies of cancer, diseases of the central nervous system and arrhythmia-related heart disease. Scand J Work Environ Health. 30(1):1-80.

3. Touitou Y, Selmaoui B. 2012. The effects of extremely low-frequency magnetic fields on melatonin and cortisol, two marker rhythms of the circadian system. Dialogues Clin Neurosci. 14(4):381-399.

4. Swanson J, Kheifets L. 2006. Biophysical mechanisms: a component in the weight of evidence for health effects of power-frequency electric and magnetic fields. Radiat Res. 165(4):470-8.

5. Grellier J, Ravazzani P, Cardis E. 2014. Potential health impacts of residential exposures to extremely low frequency magnetic fields in Europe. Environ Int. 62:55-63.

6. Kaune WT, Miller MC, Linet MS, Hatch EE, Kleinerman RA, Wacholder S, Mohr AH, Tarone RE, Haines C. 2002. Magnetic fields produced by handheld hair dryers, stereo headsets, home sewing machines, and electric clocks. Bioelectromagnetics. 23:14-25.

7. Tufani S, Ossola P, d'Amore G, Gandhi OP. 1995. Electric fields and current density distributions induced in an anatomically based model of the human head by magnetic fields froma hair dryers. Health Physics. 68:71-79.

8. WHO. 1999. What are electromagnetic fields?, http://www.who.int/pehemf/about/WhatisEMF/en/ (date of access : 16.07.2018).

9. Stronati L, Testa A, Villani P, Marino C, Lovisolo GA, Conti D, Russo F, Fresegna AM, Cordelli E. 2004. Absence of genotoxicity in human blood cells exposedto $50 \mathrm{~Hz}$ magnetic fields as assessed by comet assay, chromosome aberration, micronucleus, and sister chromatid exchange analyse. Bioelectromagnetics. 25:41-48.

10. Huuskonen H, Lindbohm ML, Juutilainen J. 1998. Teratogenic and reproductive effects of low-frequency magnetic fields. Mutation Research. 410:167-183.

11. Güler G, Türközer Z, Seyhan N. 2007. Electric field effects on guinea pig serum: the role of free radicals. Electromagn Biol Med. 26:207-223.

12. Dașdağ S, Sert C, Akdağ Z, Batun S. 2002. Effects of extremely low frequency electromagnetic fields on hematologic and immunologic parameters in welders. Arc Med Res. 33:29-32.

13. Alghamdi M, El-Ghazaly NA. 2012. Effects of exposure to electromagnetic field on some hematological parameters in mice. Open J Med Chem. 2:30-42.

14. Doğan MS, Yavaş MC, Yavuz Y, Erdoğan S, Yener I, Șimşek I, Akkuş Z, Eratilla V, Tanik A, Akdağ MZ. 2017. Effect of electromagnetic fields and antioxidants on the trace element content of rat teet. Drug Design Devel Ther. 11:1393-1398.

15. Chater S, Abdulmelek H, Pequignot JM, Sakly M, Ben Rhouma K. 2006. Effects of subacute exposure to magnetic field on blood hematological and biochemical parameters in female rats. Turk J Hematol. 23:182-187.

16. Cakir DU, Yokus B, Akdag MZ, Sert C, Mete N. 2009. Alterations of hematological variations in rats exposed to extremely low frequency magnetic fields $(50 \mathrm{~Hz})$. Arc Med Res. 40:352- 356.

17. Mansouri E, Keshtkar A, Khaki AA, Khaki A. 2016. Antioxidant effects of allium cepa and cinnamon on sex hormones and serum antioxidant capacity in female rats exposed to power frequency electric and magnetic fields. International Journal of Women's Health 
and Reproduction Sciences. 4(3): 141-145.

18. Al-Akhras MA, Ebetieha A, Hasan MK, Al-Omari I, Darmani H, Albiss B. 2001. Effects of extremely low frequency magnetic field on fertility of adult male and female rats. Bioelectromagnetics. 22(5):340-344. 